\title{
Phosphatase inhibitor, sodium stibogluconate, in combination with interferon (IFN) alpha 2b: phase I trials to identify pharmacodynamic and clinical effects
}

\author{
Taolin Yi ${ }^{1,2}$, Paul Elson ${ }^{1}$, Masato Mitsuhashi ${ }^{3}$, Barbara Jacobs ${ }^{1}$, Emese Hollovary ${ }^{1}$, \\ G. Thomas Budd ${ }^{1}$, Timothy Spiro' ${ }^{1}$, Pierre Triozzi ${ }^{1}$ and Ernest C. Borden ${ }^{1}$ \\ 1 Taussig Cancer Institute, The Cleveland Clinic, Cleveland, $\mathrm{OH}$, USA \\ 2 Department of Immunology of Lerner Research Institute, The Cleveland Clinic, Cleveland, OH, USA \\ ${ }^{3}$ Hitachi Chemical Research Center, Inc., Irvine, CA, USA \\ Correspondence to: Author, email:
}

Keywords: Cancer, phase-I-trial, phosphatase-inhibitor, IFN-a2 $\beta$, SSG

Received: December 19,2011, Accepted: December 21,2011, Published: December 22, 2011

Copyright: (C) Yi et al. This is an open-access article distributed under the terms of the Creative Commons Attribution License, which permits unrestricted use, distribution, and reproduction in any medium, provided the original author and source are credited.

ABSTRACT:

Since sodium stibogluconate (SSG) inhibited phosphatases including SHP-1 and augmented anti-tumor actions of IFN-a2b in vitro and in mice, two Phase I trials of SSG/IFN-a2b combination were undertaken to evaluate safety and target inhibition.

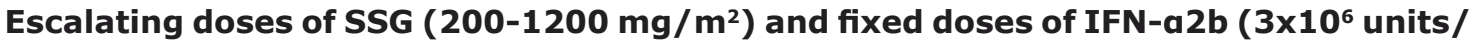
$\mathbf{m}^{2}$ ) with or without chemotherapy (dacarbazine, vinblastine, cisplatin ) were evaluated for side effects and impact on SHP-1 phospho-substrates and IFNa-stimulated-genes (ISGs) in peripheral blood in $\mathbf{4 0}$ patients with metastatic melanoma, soft tissue sarcomas, gastrointestinal stromal tumors, and breast or colorectal carcinomas who did not have other established treatment options. Common adverse events were bone marrow suppression, fatigue, gastrointestinal upset, and asymptomatic lipase elevation $(n=13)$; the latter was dose related and mostly after 10d of SSG/IFN-a2b in combination. Levels of SHP-1 substrates (pSTAT1, pSTAT3, pLck and pSIp76) were increased (up to $3 x$ ) in peripheral blood cells following SSG with no potentiation by combination with IFN-a2b. Representative ISGs in peripheral blood were induced after IFN-a2b at 4 and 24 hrs with selective modulations by combination. The median time on trials was 2.3 months (10-281d) with no objective regression of disease. Alive at $1 y$ were $17 / 40$ (43\%) patients and after $2 y$ were $8 / 40$ (20\%) following treatment initiation. These data demonstrate that SSG impacted signal molecules consistent with PTP inhibition and was tolerated in combination with IFN-a2b. Phase II investigations of SSG could safely utilize doses of up to $1200 \mathrm{mg} / \mathrm{m}^{2}$ of SSG for up to $10 \mathrm{~d}$ alone or in combination with IFN-a2b with or without chemotherapy.

\section{INTRODUCTION}

PTPs are intracellular enzymes that act as the biochemical counterparts of tyrosine kinases [1]. Since their substrates are signal transducers activated or inactivated by phosphorylation to control cell growth, death or other functions, PTPs are key switches in signaling cascades that determine the fate of different cell types. In particular, the PTP SHP-1 [src-homology 2 phosphatase-1, PTP1C, HCP, SHPTP-1, PTPN6] has been implicated as an attractive drug-targeting candidate by studies from our laboratory and others [2-6]. Expressed predominantly in cells of hematopoietic lineages [2-6], SHP-1 has been established as a key negative regulator of cytokine signaling and immune cell activation through detailed studies of mouse models of genetic SHP-1 deficiencies [7-10]. Accordingly, targeting SHP-1 with inhibitors might augment the efficacy of cytokine therapy and immunotherapy, which are in clinical use for cancer treatment. In contrast to the significant numbers of protein 
kinase inhibitors approved by FDA or under-pre-clinical and clinical evaluation for cancer treatment, few PTPs inhibitors have demonstrated pre-clinical anti-tumor activity and entered clinical trial for cancer.

Ourprior studies had identified sodium stibogluconate (SSG), a drug used for nearly 60 years to treat visceral leishmaniasis in humans [11], as a potent inhibitor of multi-PTPs that include SHP-1 and other PTPs critical in negative regulation cytokine signaling and immunity [1214]. Targeting intracellular PTPs by SSG was suggested by the reduced PTP activity of SHP-1 and SHP-2 from cells cultured in the presence of SSG $(10 \mathrm{mcg} / \mathrm{ml})[13,14]$. At clinically achievable level of the drug when administered at half the currently recommended dose $(10 \mathrm{mg} / \mathrm{kg}$ body weight), SSG inhibited recombinant SHP-1 (100\%), SHP-2 (80\%) and PTP1B (70\%) [12, 15]. Selectivity was indicated by its limited impact on recombinant MKP1 PTP under comparable conditions [12]. It is worth noting that all cancer therapeutic kinase inhibitors target multi-kinases. This may provide corresponding multiple impacts against the redundant pro-cancer mechanisms in vivo and could be critical for clinical efficacy [16]. MultiPTPs inhibitors may have clinical potential via a similar mode of operation and warrant investigation.

A negative regulatory role of SSG-sensitive PTPS in the signaling by IFNs was established in mutant mice in which the expression of the PTPs was abolished individually by genetic mutation or through gene-knockout [17-19]. Cells from these mutant mice had marked increases in response and tyrosine phosphorylation of IFNalpha2 signaling molecules (e.g., Stat1) in comparison to control cells from normal mice [17-19]. Stat1 protein was activated through tyrosine phosphorylation following IFN-alpha2b stimulation to form ISGF3 (in complex with other molecules) which subsequently binds to ISRE to regulate gene expression[20]. Consistent with targeting the negative regulatory PTPs, SSG augmented IFN-alpha2b induced tyrosine phosphorylation of Stat1 in human lymphoma cell line [14]. Augmentation of IFN-alpha2b induced Stat1 tyrosine phosphorylation by
SSG was also defined in WM9 human melanoma cells [14]. Enhanced IFN-alpha2b signaling brought about by SSG in cancer cells was coincident with the inhibition of specific intracellular target PTPs by SSG [14]. Antiproliferative activity of IFN-alpha2b was potentiated by SSG in cancer cell lines of different tissue types [14]. Median effect analysis verified that SSG and IFN-alpha2b interacted in a synergistic manner $(\mathrm{CI}<1)[21]$. The ability of SSG to enhance significantly the anti-tumor effects of IFN-alpha2b in vivo was demonstrated in a mouse model with eradication of IFN-alpha2b-refractory tumors at a tolerable dose of the drug [14].

These studies, together with the safety of SSG in clinical use [15], provided the basis for Phase I trials of the combination of IFN-alpha2b and SSG, which as a multiPTPs inhibitor has the potential to augment the anti-cancer action of the cytokine. Two Phase I trials were performed in similar patient populations. The objectives were to establish a safe dose of SSG to be used in conjunction with IFN-alpha2b for Phase II studies and to identify evidence of SHP-1 inhibition and any antitumor activity.

\section{RESULTS}

\section{Patient Characteristics and Treatment Administration}

Two trials with similar objectives were conducted. As described above, the first assessed SSG and IFNalpha2b alone and then in combination and the second SSG and IFN-alpha2b, again alone and in combination, followed by cytotoxic chemotherapy. Since the patient populations and adverse events from IFN-alpha2b and SSG in the two trials were alike, except as noted below, results were summarized together. Entered in total were 40 patients with metastatic malignancies (melanoma $\mathrm{n}=29$, soft tissue sarcomas $\mathrm{n}=5$, gastrointestinal stromal tumors $\mathrm{n}=3$, breast carcinoma $\mathrm{n}=1$, and colorectal

Table 1: Adverse Events Grade > 2 by Study and Overall*

\begin{tabular}{|c|c|c|c|c|c|c|c|c|c|}
\hline & \multicolumn{3}{|c|}{$2 Y 06$ (SSG+IFN) } & \multicolumn{3}{|c|}{3 Y06 (SSG+IFN+Chemo) } & \multicolumn{3}{|c|}{ Both Studies combined } \\
\hline & & $(n=18)$ & & & $(n=22)$ & & & $(n=40)$ & \\
\hline & & grade & & & grade & & & grade & \\
\hline Toxicity & 2 & 3 & 4 & 2 & $\underline{3}$ & 4 & $\underline{2}$ & $\underline{3}$ & 4 \\
\hline Granulocytopenia & 4 & 3 & 2 & 6 & 3 & 3 & 10 & 6 & 5 \\
\hline Thrombocytopenia & 5 & 1 & - & 3 & 3 & - & 8 & 4 & - \\
\hline Anemia & 7 & - & - & 3 & 1 & - & 10 & 1 & - \\
\hline Fatigue & 8 & 1 & - & 11 & 2 & - & 19 & 3 & - \\
\hline Fever & 2 & - & - & 7 & - & - & 9 & - & - \\
\hline G.I. upset & 2 & - & - & 9 & 3 & - & 11 & 3 & - \\
\hline Elevated lipase & 2 & 5 & 2 & 2 & 1 & 1 & 4 & 6 & 3 \\
\hline Hypokalemia & - & - & - & - & 3 & - & - & 3 & - \\
\hline
\end{tabular}

*Attributed (at le ast possibly) to treatment. Of greatest severity by patient while on treatment 
carcinoma $n=2$ ). These were patients for whom therapies of established effectiveness did not exist (prior radiation had been received by 13 and prior chemotherapy by 27). They were of median age of 53 (range 28-79), more of male gender $(n=24)$, and mostly Caucasians $(n=38)$. All patients were eligible and of ECOG performance status 0 or 1.

\section{Side effects}

The most common instances of adverse events, worse than mild and considered possibly related to treatment from the combined continuous administration of the treatment regimens in the two trials, were granulocyte reduction $(n=21)$, fatigue $(n=22)$, gastrointestinal upset $(n=14)$, fever (9), platelet reduction $(n=12)$, anemia $(n=11)$, lipase elevation $(n=13)$, and hypokalemia $(n=3)$ (Table 1). At least one attributed severe or life-threatening event occurred in 27 (68\%) of patients, which were most frequently the expected bone marrow suppression from IFN-alpha2b \pm chemotherapy ( $\mathrm{n}=15$ patients). Other severe or life-threatening adverse events associated with treatment, all ones previously associated with these drugs on other trials, were instance of lipase elevations $(n=5)$, hypokalemia $(n=3)$, and fatigue $(n=3)$ (Table 1$)$.

Asymptomatic lipase elevations $(n=13)$ occurred most commonly after $10 \mathrm{~d}$ of SSG in combination with IFN-alpha $2 \mathrm{~b}$ and were related to dose ( $p=0.04$ by Fisher's exact test of $<800 \mathrm{mg} / \mathrm{m}^{2}$ to $\geq 800 \mathrm{mg} / \mathrm{m}^{2}$ ). Neutropenia and thrombocytopenia resulting from IFN-alpha $2 b$ at the highest dose of SSG $\left(1200 \mathrm{mg} / \mathrm{m}^{2}\right)$ when compared to the lowest doses (200 or $400 \mathrm{mg} / \mathrm{m}^{2}$ ) were not significantly potentiated by the addition of SSG (data not shown).

Progressive disease was the cause for terminating treatment in 28 patients. Five patients completed all planned cycles of treatment. Five patients were removed from study for adverse events $(n=2$ hypokalemia and one each of grade 4 lipase elevation, recurring neutropenia, and recurring nausea and vomiting). On a fourth cycle of treatment on the combination chemotherapy program after three relatively uncomplicated prior cycles, one patient died at a local hospital of a intra-cerebral event that could have been related to underlying disease or to treatment. Regardless of attribution 16/40 patients were assessed as having a one level decline in ECOG performance status and two patients as having $\geq 2$ level declines before removal from study. Median weight loss was $2.3 \mathrm{~kg}$ (mean

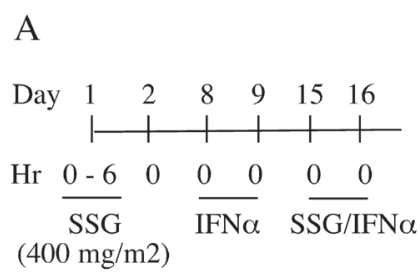

$\mathrm{C}$

\begin{tabular}{lccccc}
\hline & \multicolumn{5}{c}{ Cellular levels $(\mathrm{x})$} \\
& 0 & 1 & 2 & 3 & 6 \\
\cline { 2 - 6 } & & & & \\
pST) & \\
pSTAT3 & 1 & 2.5 & 2 & 3 & 2.6 \\
pLck & 1 & 2.4 & 3 & 2.3 & 2 \\
pSlp76 & 1 & 2.4 & 3.2 & 4.1 & 4.0 \\
& 1 & 1 & 1 & 1 & 2.8
\end{tabular}
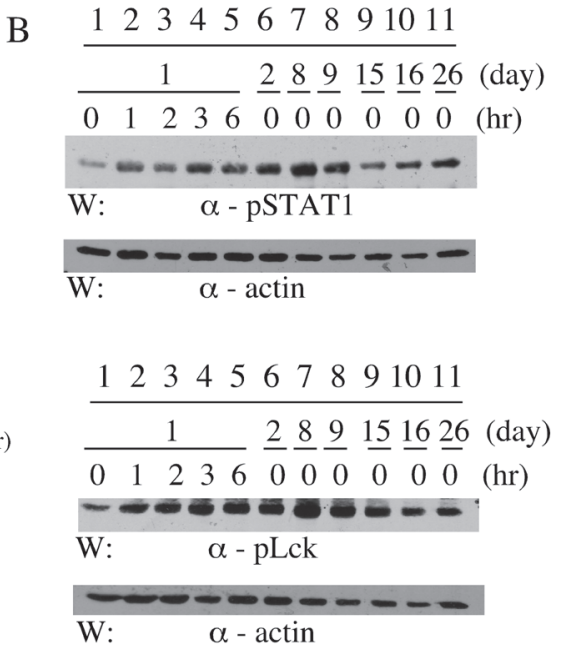

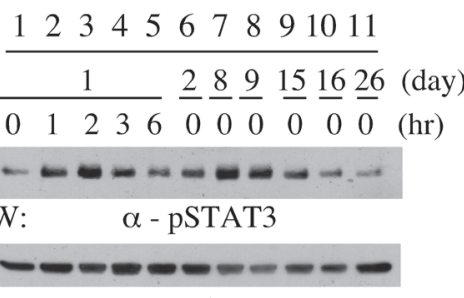

W:

$$
\alpha-\operatorname{actin}
$$

$\begin{array}{llllllllllll}1 & 2 & 3 & 4 & 5 & 6 & 7 & 8 & 9 & 1011\end{array}$

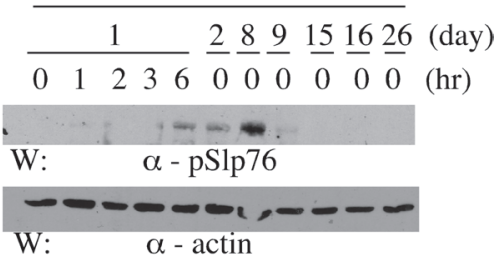

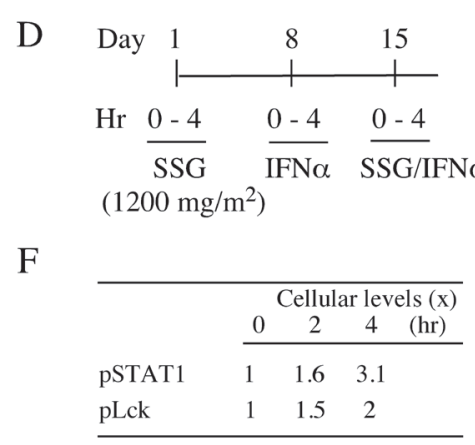

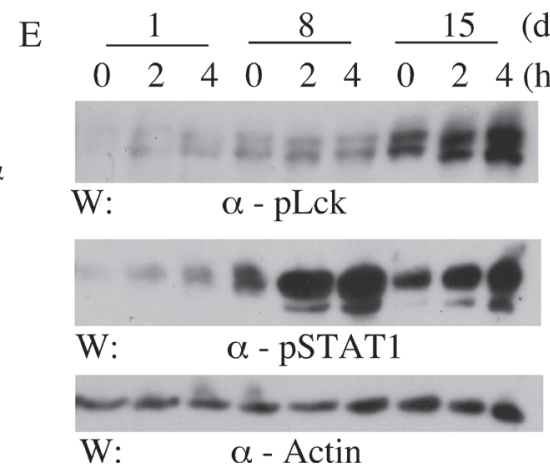

Figure 1: SSG modulates peripheral blood cell phospho-proteins in patients. Peripheral blood samples were collected pre- and post-treatments from patients as indicated (A and D). Selective phospho-proteins in the samples were evaluated by SDS-PAGE/Western blotting with antibodies as indicated (B and $\mathrm{E}$ ). The relative levels of the phospho-proteins were quantified by densitometry $(\mathrm{C}$ and $\mathrm{F})$. 
loss of $3.0 \pm 3.5 \mathrm{SD}$ ) $\mathrm{kg}$ (range -14.6 to $+3.0 \mathrm{~kg}$ ). Although progressive malignancy may have contributed, 13 patients lost more than 5\% (grade 1) from starting weight during the period on treatment. Anorexia worse than mild was, however, reported in only two patients.

\section{Peripheral blood cellular phospho-proteins}

Given the putative targeting of PTPs by SSG, the impacts on selective phospho-proteins in peripheral blood cells were investigated in two cases (Fig 1). The selected molecules are reported substrates of the SSG-sensitive phosphatases and essential for $\mathrm{T}$ cell activation ( $\mathrm{pLck}$, pZap70 and pSlp76) or for IFN-alpha signaling (pSTAT1) $[18,22-26]$. SSG monotherapy increased pSTAT1 levels (up to $3 \mathrm{x}$ ) (Fig $1 \mathrm{C}$ and F), treated at $400 \mathrm{mg} / \mathrm{m}^{2}$ and $1,200 \mathrm{mg} / \mathrm{m}^{2}$ respectively (Fig $1 \mathrm{~A}$ and D). It was evident within $1 \mathrm{hr}$ post-treatment with durations up to $6 \mathrm{hrs}$ (Fig 1B). Similar increases in pSTAT3 and pLck levels following SSG were detected (Fig 1B) whereas increases of pSlp76 were evident at later time points (Fig 1B). A prolonged impact up to day 8 was apparent for pSTAT1, pLck and pSlp76 following a single dose of SSG on day 1 (Fig 1B, comparing lane 1 and 7). However, there was no obvious augmentation of IFN-alpha-induced pSTAT1 or pSTAT3 by SSG (Fig 1B and E) although pLck levels were markedly higher following SSG/IFN-alpha cotreatment (Fig 1E). The levels of pZap70 and pLAT were undetectable under the experimental conditions (data not shown).

\section{ISG product induction}

To determine whether SSG augmented expression of RNA of ISGs, 4 patients were assessed for changes in STAT1, IRF7, XAF1, and G1P2 at $24 \mathrm{hrs}$ after SSG at 800 or $1200 \mathrm{mg} / \mathrm{m}^{2}$, IFN-alpha $2 \mathrm{~b}$, or the combination. These confirmed expected induction at 24 hours after IFNalpha $2 b$ on day 9 but no consistent broad ISG increase after the combination (Fig 2). RNA samples from three other patients treated with SSG at $1200 \mathrm{mg} / \mathrm{m}^{2}$ were assessed after 4 hours each treatment identified increases in STAT1, IRF7, XAF1, G1P2, TRAIL, CXCL10, and AIM2 after IFN-alpha2 alone but with no differing results to suggest general broad potentiation of gene expression by SSG with IFN-alpha2 (data not shown). RNA expression levels of a panel of $\sim 50$ genes with immune modulatory potential, whose level might be affected by SSG or IFNalpha2b were also assessed with no evidence of general potentiation (Supplemental Table 1).

To assess protein product change of ISGs, 7 patients treated at SSG $800 \mathrm{mg} / \mathrm{m}^{2}$ had representative ISG proteins, quantitated in serum by ELISA prior to treatment and 24 hours after each treatment. Beta2-microglobulin, TRAIL, CCL8, and CXCL11 all had expected increases 24 hours after IFN-alpha2 with return to near baseline after two days off and prior to SSG but no potentiation after the latter combined with IFN-alpha2b (Fig 3). Other proteins products of potentially modified gene expression assessed in serum after each treatment included IP-10 and IL-10; no consistent change was identified.

Antimony levels as a measure of achieved serum concentration of SSG, when measured 30 and 60 minutes after infusion at $800 \mathrm{mg} / \mathrm{m}^{2}$, exceeded $20 \mathrm{mcg} /$ $\mathrm{ml}$ in $5 / 5$ patients. We had identified this as a desired
A

$\begin{array}{cccc}\text { Day } & 1-2 & 8-9 & 15-16 \\ \operatorname{Hr} & \frac{0-24}{\mathrm{SSG}} & \frac{0-24}{\mathrm{IFN} \alpha} & \frac{0-24}{\text { SSG/IFN } \alpha}\end{array}$

B

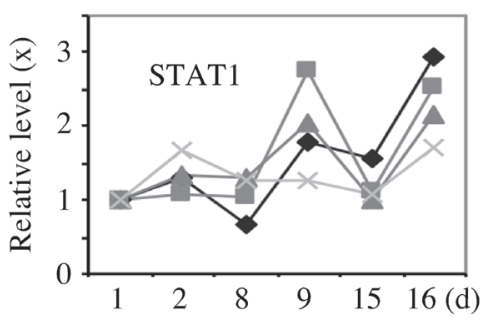

$\mathrm{D}$

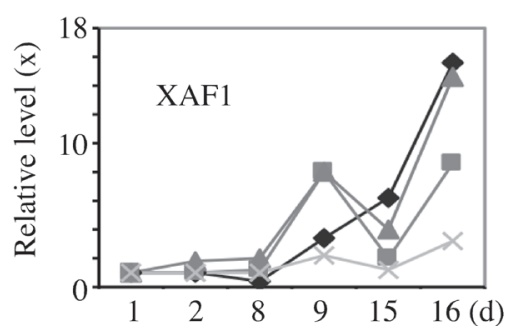

C

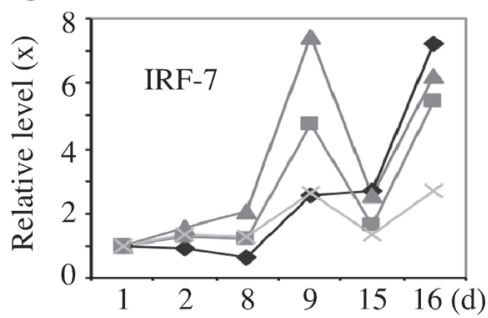

$\mathrm{E}$

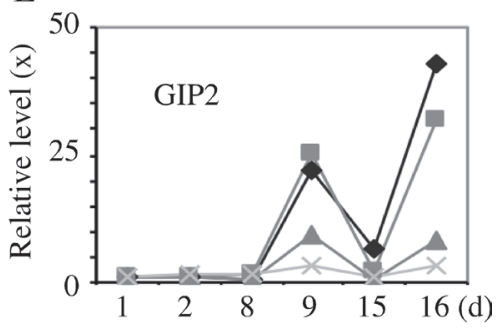

Figure 2: Peripheral transcripts levels of selective ISGs in patients. Peripheral blood samples were collected pre- and posttreatments from 4 patients as indicated (A). The relative levels (fold change) of transcripts for STAT1, IRF-7, XAF1 and GIP2 were quantified by quantitative RT-PCR (B-E). Each symbol in panel B-E indicates a different patient. 
target concentration based upon complete inhibition of recombinant SHP-1 (100\%)[12, 15].

\section{Treatment outcomes}

No patient had objective regression of disease. The median time on trial was 2.3 months (range 10-281d). Although possibly influenced by prior treatment, patients receiving the chemotherapy regimen in addition to $\mathrm{SSG}$ and IFN-alpha2b were on study longer (median 81d) than those on only SSG and IFN-alpha2b (median 53d, $p=0.002$ by Wilcoxon rank sum test). Of these patients with metastatic solid tumors, alive at $1 \mathrm{y}$ were $17 / 40$ $(43 \%)$ patients with $8 / 40(20 \%)$ patients alive for $>2$ years after initiation of investigational treatment. The patients with $>$ 2-year survival included six with melanoma, one with a gastrointestinal stromal tumor and one with hepatic angiosarcoma. All entered patients have now had treatment discontinued.

\section{DISCUSSION}

SSG, a drug effective for chronic leishmaniasis [11], was a multi-PTPs inhibitor and augmented anti-cancer activity of IFN-alpha2b in mouse models [11-14]. Since it is selectively toxic to intracellular bur not free-living forms of the parasite [27-30] and intracellular survival of the pathogen in macrophages involves attenuation of cytokine signaling through PTPs [31], inhibition of PTPases may also provide an explanation for its antiparasitic activity. IFN-alpha2b-induced ISGF3 ISRE complex formation may be negatively regulated by PTPs. In support, SSG augmented IFN-alpha2b-induced ISGF3 ISRE complex formation in melanoma cells [14], consistent with an inhibitory action for PTPs. Additional evidence in support of the enhanced IFN-alpha2b signaling through the mechanism of PTP inhibition by SSG was derived from a cancer cell line that has defective intracellular IFN signaling and failed to respond to the combination of SSG and IFN- $\alpha 2 b[14,32]$. Following a 3-week course of IFN- $\alpha 2 \mathrm{~b}$ ( $5 \times 10^{5} \mathrm{U} /$ daily subcutaneously) alone, partial $(\sim 50 \%)$ growth inhibition of WM9 human melanoma tumors in nude mice resulted [14]. When combined with SSG (12 mg/day subcutaneously, IFN-alpha resulted in tumor regression and complete eradication of the tumors by the third week of study with long term tolerance for more than 10 weeks [14].

We sought to establish clinical safety of SSG alone and in combination with IFN-alpha2b and to identify evidence of SHP-1 inhibition. Forty patients with Stage IV metastatic malignancies were treated on the two protocols of Phase I design to identify toleration of doses of the investigational agent SSG escalated from 200-1200 mg/ $\mathrm{m}^{2}$ with either a fixed dose IFN-alpha2b or in combination with fixed doses of IFN-alpha2b, dacarbazine, vincristine, and cisplatin. Of adverse events expected from previous investigations with SSG (hypokalemia, increased amylase, and increased lipase), only increased lipase and hypokalemia occurred in a substantial number of patients (grade 3 or 4 elevations in 22.5 and $7.5 \%$ of patients respectively). The asymptomatic, reversible lipase elevations were dose related $(p=0.04)$. Many of the grade 3 or 4 adverse events that did occur may have been due to progressive disease or the other drugs utilized rather than the investigational agent SSG. With appropriate assessment for adverse events, future investigations might consider utilizing doses of $1200 \mathrm{mg} / \mathrm{m}^{2}$ of SSG intravenously for up to $10 \mathrm{~d}$ in combination with IFNalpha2b with or without chemotherapy. Similar to our findings of acceptable tolerance of SSG in combination with IFN-alpha2b in cancer patients were findings in a concomitant study of similar design [33]. Both trials found that Phase II investigation of SSG could safely
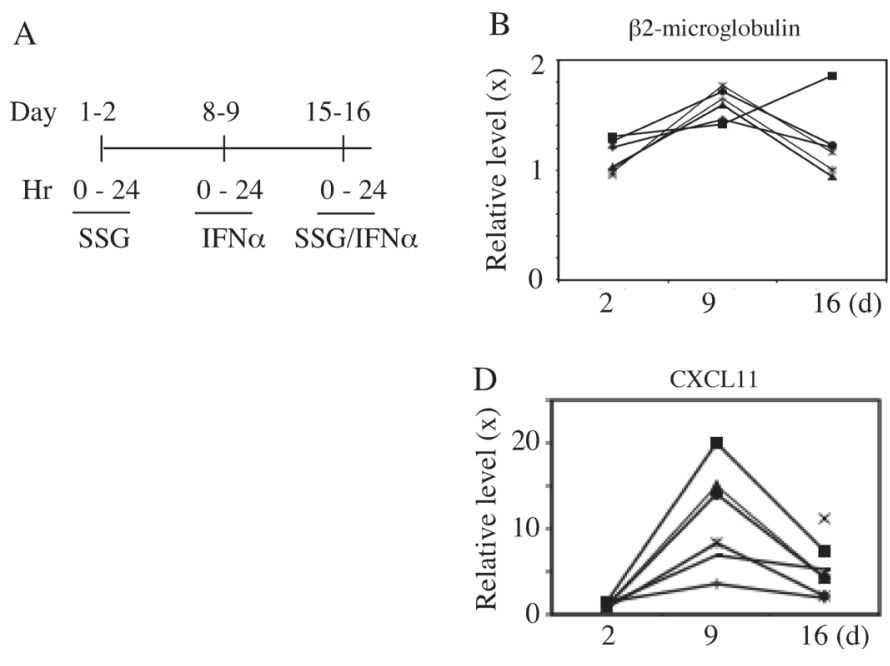
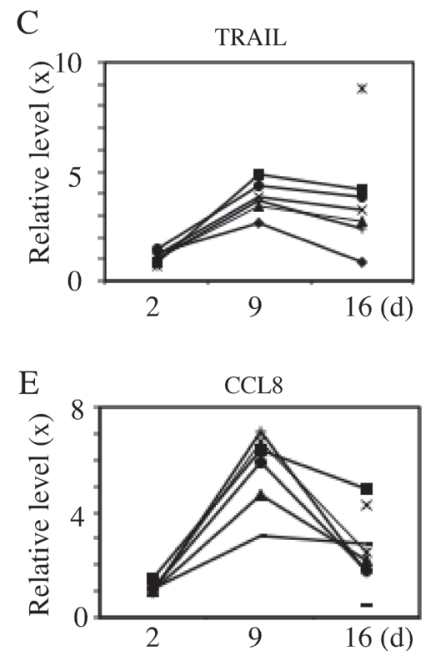

Figure 3: Peripheral protein levels of selective ISGs in patients. Peripheral blood samples were collected at time points pre- and post-treatments from patients as indicated (A). The relative sera protein levels (ratio) of Beta2 microglobulin, TRAIL, CXCL11 and CCL8 were quantified by ELISA (B-E). Each symbol in panel B-E indicates a different patient. 
utilize doses $>800$ and potentially $1200 \mathrm{mg} / \mathrm{m}^{2}$ for up to $10 \mathrm{~d}$ in combination with IFN-alpha $2 \mathrm{~b}$ and, based upon our results, with addition of chemotherapy. Thus clinical use of a PTP inhibitor to potentiate other anti-tumor modalities is feasible.

IFN-alpha2 is established for treatment of hepatitis $\mathrm{C}$ virus, melanoma, and other malignancies [34]. IFNs have potent and pleiotropic gene regulatory effects in melanoma, antitumor activity for syngeneic murine melanomas, human melanoma xenografts, and effectiveness in patients with resected primaries at high risk for recurrence $[34,35]$. Identifying and dissecting the relative role of the genes induced by IFNs that modulate pleiotropic effects of proteins on the tumor cell surface, alter levels of receptors for other cytokines, and activities of enzymes and cytokines that modulate cellular growth, function, and apoptosis, remains under investigation for targeting anti-tumor effects [36]. RNA expression of most ISGs did not seem to be potentiated by SSG but augmentation of selective ISGs may result as suggested by the heightened levels of XAF1 and GIP1 (Fig 2). This would need further confirmation and, if verified in larger studies, could be of specific ISGs for defining effects of SHP-1 inhibition.

SHP-1 is a critical negative regulator in anti-tumor immune cells that include T cells [37], NK cells [38], dendrocytes and macrophages [39]. Importantly, the PTP controls T cell activation [40] by reducing the sensitivity of the T cell receptor (TCR) to antigen $[41,42]$ and terminates TCR signals by dephosphorylating and inactivating essential components of TCR signaling cascade (e.g., Lck, Zap70 and Slp76) [43]. In NK cells, SHP-1 is coupled to inhibitory receptors for MHC class I antigen to prevent NK cell activation [44]. SSG was shown by our laboratory to inhibit SHP-1 [12], synergize with IFN-alpha to cure melanoma tumors in mice [14], and interact with IL-2 in anti-tumor action via a $\mathrm{T}$ cell-dependent mechanism [45]. An independent group demonstrated the capacity of SSG in vitro to help reversing $\mathrm{T}$ cell anergy among tumor infiltrating lymphocytes (TILs) from human melanoma, renal cancer and non-small cell lung carcinoma [46]. This is of particular interest given the reported suppression of TCR signaling and lytic function of $\mathrm{CD}^{+}$TIL cells by SHP-1 [47].

In this clinical trial, the target serum level of SSG for SHP-1 inhibition was exceeded by more than two folds. Despite what may have been limitations in assay methodologies for detecting labile phosphor-proteins, a suggestion that prolonged phosphoryation of $\mathrm{T}$ and $\mathrm{NK}$ cell signaling proteins inhibited by phosphatases may have resulted (Fig 1). In the parallel study patients receiving the higher doses $\left(\geq 900 \mathrm{mg} / \mathrm{m}^{2}\right)$ of SSG had a significantly lower number of Treg cells and myeloid dendritic cells together with a higher percentage of natural killer (NK) cells that synthesized perforin and of plasmacytoid dendritic cells (pDC) that secreted IFN-gamma in response to activation [33]. These findings suggest that in humans in addition to mice, SSG can have modulatory activity influencing innate and acquired immunity.

PTPs include enzymes that are oncogenic, tumor suppressive or immune regulatory [1, 3, 5, 48-50]. PTPs are thus key players in human malignancies and may have potential for developing inhibitors as novel cancer therapeutics [1, 5, 49-51]. Our data suggested tolerance of a SHP-1 inhibitor, SSG, in combination with IFN-alpha2b in cancer patients with evidence of immune regulatory activity in this study and one undertaken in parallel. Clinical inhibitors of SHP PTPs other than SSG have not been evaluated. These findings support developing more potent and selective PTP inhibitors for cancer treatment. Indeed, several small molecule inhibitors for selective PTPs, more potent than SSG, have been identified in recent studies and have had significant anti-tumor activities in pre-clinical models [52, 53]. Further development and evaluations of other PTPs inhibitors are warranted and have promise as targeted therapeutics for effective and safe cancer treatments.

\section{PATIENTS AND METHODS}

\section{Inclusion and exclusion criteria}

All patients met the following eligibility criteria: histological diagnosis of metastatic malignancy, measurable disease as defined by the NCI Response Evaluation Criteria in Solid Tumors (RECIST) guidelines, performance status (ECOG) of $0-2$, recovered $>3$ weeks from the any radiation therapy, not have received any adjuvant or metastatic disease IFN-alpha $2 \leq 4$ months prior, no other established treatment options, and no major surgery within 28 days, together with granulocyte count $\geq$ $1.5 \times 10^{9} / \mathrm{L}$, platelets $\geq 100 \times 10^{9} / \mathrm{L}$, creatinine $<1.0 \times$ upper limit normal (ULN), bilirubin $<1.5 \times$ ULN, AST $<1.5 \mathrm{x}$ ULN, and ALT $<1.5 \times$ ULN, and must have provided written informed consent as to the investigative nature of treatment in accordance with institutional and federal guidelines. Excluded were patients with uncontrolled CNS metastases in the prior 3 months, chronic infections, history of arrhythmia with baseline ECG abnormalities suggestive of conduction delay, i.e. $1^{0}$ or greater atrioventricular block complete or incomplete (QRS > 120 $\mathrm{ms}$ ) bundle branch block, or suggestive of repolarization abnormalities, i.e. QTc $\geq 0.48 \mathrm{sec}$, congestive heart failure, pregnant or lactating women, fertile women or men unless surgically sterile or using effective contraception, evidence of HIV or HBsAg, organ allografts, high dose glucocorticoids, age $<18$, or history of severe psychiatric disorders. 


\section{Treatment plan}

Cohorts of patients were enrolled at dose levels of SSG of $200,400,800$, and $1200 \mathrm{mg} / \mathrm{m}^{2} /$ day on days $1-5$ and 8-12 and IFN-alpha2b alone at a dose of $3 \mathrm{MU} / \mathrm{m}^{2}$ subcutaneously daily for $14 \mathrm{~d}$. The starting dose of SSG was chosen to be less than that used for daily treatment of visceral leishmaniasis $\left(800 \mathrm{mg} / \mathrm{m}^{2} /\right.$ day $)$ and the IFNalpha $2 \mathrm{~b}$ dose to be substantially less than the maximally tolerated. To enable pharmacodynamic assessments of each agent alone, schedule and dose initiation was with a single administration of SSG on the first day, IFN-alpha $2 \mathrm{~b}$ beginning a week later for $5 \mathrm{~d}$, and the combination beginning on day 15 for two weeks. SSG dose was escalated with successive cohorts but not escalated within cohorts. Treatment for two weeks continued at $28 \mathrm{~d}$ intervals until disease progression or dose limiting toxicity (DLT) occurred.

Both trials used a standard $3+3$ dose escalation design to determine the maximal tolerated dose (MTD) of SSG, with escalation being based on the number of dose-limiting toxicities observed (grade $\geq 3$ treatmentrelated adverse event by CTCAE 3.0 criteria that persisted despite medical treatment/prophylaxis, or grade 2 cardiovascular arrhythmia in the absence of hypokalemia or hypomagnesemia). That is, cohorts of three patients were initially treated at a particular SSG dose. If none of these patients experienced DLT, SSG was to be escalated to the next higher dose level. If two or more patients experienced DLT, the trial was to be stopped and the next lower dose defined as the MTD. If one patient had DLT, three additional patients were to be treated at that dose, with escalation occurring if no additional DLT was observed. Patients were assessed for adverse events weekly for 4 weeks, biweekly for 2 weeks, and then monthly. Measureable disease was assessed at each visit and by imaging every 2 months. Adverse events were measured and graded according to Common Terminology Criteria for Adverse Events (CTCAE) (NIH 2003).

After validation of lack of unexpected adverse events in the initial patients, a second protocol in combination with chemotherapy was initiated with parallel eligibility criteria (eligibility for Stage IV patients without measureable disease for up to four cycles of treatment added). This utilized dose levels of SSG of 200, 400, 800, and $1200 \mathrm{mg} / \mathrm{m}^{2} /$ day for four days with IFN-alpha2b at a dose of $3 \mathrm{MU} / \mathrm{m}^{2}$ subcutaneously daily for $4 \mathrm{~d}$. Again for pharmacodynamic assessments, SSG and IFN-alpha2b alone and then in combination were initiated as a single administrations of SSG on the first day, beginning a week later $3 \mathrm{MU} / \mathrm{m}^{2}$ for $5 \mathrm{~d}$, and a chemotherapy combination initiated beginning a week thereafter for $2 \mathrm{~d}$ with cisplatin at a dose of $30 \mathrm{mg} / \mathrm{M}^{2} \mathrm{IV}$, vinblastine $2.0 \mathrm{mg} / \mathrm{M}^{2} \mathrm{IV}$, and dacarbazine $350 \mathrm{mg} / \mathrm{m}^{2}$ IV with each chemotherapy dose given daily. Cycles were repeated every $28 \mathrm{~d}$.

The studies were conducted under IND \# 68881 from the FDA with the clinical grade SSG for investigational study in the US provided by Albert David Inc, Calcutta and with commercially available IFN-alpha $2 b$ from Schering Merck. The protocols (IRB 2Y06 and IRB3Y06) were conducted with approval from and under the auspices of the Investigational Review Board of the Case Comprehensive Cancer Center and were registered as CT.gov NCT00311558 and NCT00498979 respectively.

\section{ELISA assays for ISG products}

Beta $_{2}$-microglobulin (R\&D Systems, Minneapolis, $\mathrm{MN}$ ) was quantitated in patients' sera using a competitive binding enzyme immunoassay. TRAIL, CXCL11, and CCL8 (MCP-2) (RayBiotech, Raitan, NJ) were quantitated in frozen stored patients' sera using individual quantitative sandwich enzyme immunoassays for batched samples. The lower limits of sensitivity for the ELISA assays ranged from $0.2 \mathrm{ug} / \mathrm{ml}$ for Beta 2 microglobulin, $2.9 \mathrm{pg} / \mathrm{ml}$ for TRAIL, $14 \mathrm{pg} / \mathrm{ml}$ for CXCL11 and $1.5 \mathrm{pg} /$ $\mathrm{ml}$ for CCL8.

\section{RNA collection and analyses}

Blood was collected in PAX tubes (PreAnalytiX Inc., Franklin Lakes, NJ) at pre treatment and day 8, and RNA was prepared using the PreAnalytiX Blood RNA kit according to manufacturer's instructions. cDNA was prepared using the SuperScript III FirstStrand Synthesis System (Invitrogen Inc. Carlsbad, CA) according to instructions of the manufacturer. Selected gene expression was assessed by iTaq SYBR (BioRad and ABI7900, cycler [54]. Primer sequences were G1P2: CAAATGCGAC GAACCTCTGA, CCGCTCACTT GCTGCTTCA, XAF1:CCTAGAGGAGATAAAGCAGC CTATGA, AAGCTAACCA CCGGCATTTCT, IRF7: TCCCCACGCT ATACCATCTA CCT, ACAGCCAGGG TTCCAGCTT and STAT1: GTGGAAAGAC AGCCCTGCAT, ACTGGACCCC TGTCTTCAAG AC. GAPH was used to normalize CT values and fold expression was calculated based on pretreatment CT values using the ddCT formula.

\section{Antimony quantification}

Antimony, a constituent of SSG [55], has been used to assess SSG serum concentration. It was quantitated by ARUP at the University of Utah by inductively coupled plasma/mass spectrometry, reference range $0-6$ microg/L. 


\section{Phospho-proteins in peripheral blood}

Heparinized peripheral blood samples were obtained by vein-puncture per clinical trial protocols approved by the Institutional Review Board (IRB) of Cleveland Clinic. For evaluation of phospho-proteins, the samples were diluted $(5 \mathrm{x})$ with cold hypotonic solution $(10 \mathrm{mM}$ Tris, $\mathrm{pH} 7.4 ; 10 \mathrm{mM} \mathrm{NaCl} ; 0.2 \mathrm{mM} \mathrm{Na}_{3} \mathrm{VO}_{4}$ ) to lyse $\mathrm{RBC}$ and washed $2 \mathrm{x}$ with the solution. The WBC pellets were lysed in cold lysis buffer (1\% NP40, $50 \mathrm{mM}$ Tris, $\mathrm{pH} 7.4$, $150 \mathrm{mM} \mathrm{NaCl}, 20 \mathrm{mM} \mathrm{NaF}, 0.2 \mathrm{mM} \mathrm{Na}_{3} \mathrm{VO}_{4}$ and $1 \mathrm{mM}$ $\mathrm{Na}_{3} \mathrm{MO}_{4}$ ) containing a cocktail of proteinase inhibitors (Sigma, 1 tablet $/ 10 \mathrm{ml}$ ). The lysates were cleared by centrifuging $(14,000 \mathrm{rpm}, 10 \mathrm{~min})$ in a microfuge at $4^{\circ} \mathrm{C}$ to remove insoluble parts, mixed with equal volume of 2 x SDS-PAGE sample buffer, boiled for $5 \mathrm{~min}$ and analyzed by SDS-PAGE/Western blotting. Relative intensities of phosphotyrosine bands were quantified through densitometry analysis. Antibodies against pStat 1 (New England Biolab), pStat3 (Santa Cruz Biotech), pLck (Cell Signaling), pZap70 (BD Biosciences), pSlp76 (BD Biosciences) and pLat (BD Biosciences) were from commercial sources

\section{ACKNOWLEDGEMENTS}

Contributions of Mingli Cao, Mike Berk and Teresa Markle in technical assistance, Denise Robson, Margaret Terry, and Matthew Rump to clinical data analysis and verification, Mr. H. P. Kapra of Albert David Inc in Calcutta for clinical grade SSG that met standards of the FDA for investigative clinical study and Schering Plough for a complementary supply of commercial IFN-alpha2b are gratefully recognized. This publication was made possible by the Case Western Reserve University/Cleveland Clinic CTSA Grant Number UL1 RR024989 from the National Center for Research Resources (NCRR), a component of the National Institutes of Health and NIH roadmap for Medical Research. Its contents are solely the responsibility of the authors and do not necessarily represent the official view of NCRR or NIH.

\section{Grant Support}

The study was supported by R01 CA115492 (EB) and 096636 (TY), a gift from Carlos and Maria Tejada because of their interest in Sb chemistry and new treatments for melanoma, and support from the Taussig Cancer Institute.

\section{AUTHORS'S DISCLOSURE}

Patents on SSG have been issued to TY.

\section{REFERENCES}

1. Tonks NK. Protein tyrosine phosphatases: from genes, to function, to disease. Nat Rev Mol Cell Biol. 2006;7:833-46.

2. Lorenz U. SHP-1 and SHP-2 in T cells: two phosphatases functioning at many levels. Immunological reviews. 2009;228:342-59.

3. Neel BG, Gu H, Pao L. The 'Shp'ing news: SH2 domaincontaining tyrosine phosphatases in cell signaling. Trends Biochem Sci. 2003;28:284-93.

4. Shultz LD, Rajan TV, Greiner DL. Severe defects in immunity and hematopoiesis caused by SHP-1 proteintyrosine-phosphatase deficiency. Trends Biotechnol. 1997; 15:302-7.

5. Yi T, Lindner DJ. The role and target potential of protein tyrosine phosphatases in cancer. Current Oncology Reports. 2008;10:114-21.

6. Zhang J, Somani AK, Siminovitch KA. Roles of the SHP1 tyrosine phosphatase in the negative regulation of cell signalling. Semin Immunol. 1999;12:361-78.

7. Croker BA, Lawson BR, Rutschmann S, Berger M, Eidenschenk $\mathrm{C}$, Blasius $\mathrm{AL}$, et al. Inflammation and autoimmunity caused by a SHP1 mutation depend on IL1, MyD88, and a microbial trigger. Proceedings of the National Academy of Sciences of the United States of America. 2008;105:15028-33.

8. Fowler CC, Pao LI, Blattman JN, Greenberg PD. SHP-1 in $\mathrm{T}$ cells limits the production of $\mathrm{CD} 8$ effector cells without impacting the formation of long-lived central memory cells. Journal of immunology. 2010;185:3256-67.

9. Shultz LD, Schweitzer PA, Rajan TV, Yi T, Ihle JN, Matthews RJ, et al. Mutations at the murine motheaten locus are within the hematopoietic cell protein-tyrosine phosphatase (Hcph) gene. Cell. 1993;73:1445-54.

10. Tsui HW, Siminovitch KA, de Souza L, Tsui FW. Motheaten and viable motheaten mice have mutations in the haematopoietic cell phosphatase gene. Nature Genetics. 1993;4:124-9.

11. Berman JD. Chemotherapy for leishmaniasis: biochemical mechanisms, clinical efficacy, and future strategies. Rev Infect Dis. 1988;10:560-86.

12. Pathak MK, Yi T. Sodium stibogluconate is a potent inhibitor of protein tyrosine phosphatases and augments 
cytokine responses in hemopoietic cell lines. J Immunol. 2001;167:3391-7.

13. Pathak MK, Hu X, Yi T. Effects of sodium stibogluconate on differentiation and proliferation of human myeloid leukemia cell lines in vitro. Leukemia. 2002;16:2285-91.

14. Yi T, Pathak MK, Lindner DJ, Ketterer ME, Farver C, Borden EC. Anticancer activity of sodium stibogluconate in synergy with IFNs. J Immunol. 2002;169:5978-85.

15. Herwaldt BL, Berman JD. Recommendations for treating leishmaniasis with sodium stibogluconate (Pentostam) and review of pertinent clinical studies. Am J Trop Med Hyg. 1992;46:296-306.

16. Morphy R. Selectively nonselective kinase inhibition: striking the right balance. J Med Chem. 2010;53:1413-37.

17. David M, Chen HE, Goelz S, Larner AC, Neel BG. Differential regulation of the alpha/beta interferonstimulated Jak/Stat pathway by the $\mathrm{SH} 2$ domaincontaining tyrosine phosphatase SHPTP1. Mol Cell Biol. 1995;15:7050-8.

18. You M, Yu DH, Feng GS. Shp-2 tyrosine phosphatase functions as a negative regulator of the interferon-stimulated Jak/STAT pathway. Mol Cell Biol. 1999;19:2416-24.

19. Myers MP, Andersen JN, Cheng A, Tremblay ML, Horvath CM, Parisien JP, et al. TYK2 and JAK2 are substrates of protein-tyrosine phosphatase 1B. J Biol Chem. 2001;276:47771-4.

20. Darnell JE, Jr. Studies of IFN-induced transcriptional activation uncover the Jak-Stat pathway. J Interferon Cytokine Res. 1998;18:549-54.

21. Chou TC, Talalay P. Quantitative analysis of dose-effect relationships: the combined effects of multiple drugs or enzyme inhibitors. Adv Enzyme Regul. 1984;22:27-55.

22. Binstadt BA, Billadeau DD, Jevremovic D, Williams BL, Fang N, Yi T, et al. SLP-76 is a direct substrate of SHP-1 recruited to killer cell inhibitory receptors. J Biol Chem. 1998;273:27518-23.

23. Chiang GG, Sefton BM. Specific dephosphorylation of the Lck tyrosine protein kinase at Tyr-394 by the SHP-1 proteintyrosine phosphatase. J Biol Chem. 2001;276:23173-8.

24. Plas DR, Johnson R, Pingel JT, Matthews RJ, Dalton M, Roy G, et al. Direct regulation of ZAP-70 by SHP-1 in T cell antigen receptor signaling. Science. 1996;272:1173-6.

25. Stefanova I, Hemmer B, Vergelli M, Martin R, Biddison WE, Germain RN. TCR ligand discrimination is enforced by competing ERK positive and SHP-1 negative feedback pathways. Nature immunology. 2003;4:248-54.

26. Wu TR, Hong YK, Wang XD, Ling MY, Dragoi AM, Chung AS, et al. SHP-2 is a dual-specificity phosphatase involved in Stat1 dephosphorylation at both tyrosine and serine residues in nuclei. The Journal of biological chemistry. 2002;277:47572-80.

27. Kemp M, Kurtzhals JA, Kharazmi A, Theander TG. Interferon-gamma and interleukin-4 in human Leishmania donovani infections. Immunol Cell Biol. 1993;71 ( Pt 6):583-7.

28. Murray HW, Delph-Etienne S. Roles of endogenous gamma interferon and macrophage microbicidal mechanisms in host response to chemotherapy in experimental visceral leishmaniasis. Infect Immun. 2000;68:288-93.

29. Alexander J, Carter KC, Al-Fasi N, Satoskar A, Brombacher F. Endogenous IL-4 is necessary for effective drug therapy against visceral leishmaniasis. Eur J Immunol. 2000;30:2935-43.

30. Berman JD, Wyler DJ. An in vitro model for investigation of chemotherapeutic agents in leishmaniasis. J Infect Dis. 1980;142:83-6.

31. Nandan D, Yi T, Lopez M, Lai C, Reiner NE. Leishmania EF-1alpha activates the Src homology 2 domain containing tyrosine phosphatase SHP-1 leading to macrophage deactivation. J Biol Chem. 2002;277:50190-7.

32. Matin SF, Rackley RR, Sadhukhan PC, Kim MS, Novick AC, Bandyopadhyay SK. Impaired alpha-interferon signaling in transitional cell carcinoma: lack of p48 expression in 5637 cells. Cancer Res. 2001;61:2261-6.

33. Naing A, Reuben JM, Camacho LH, Gao H, Lee BN, Cohen EN, et al. Phase I Dose Escalation Study of Sodium Stibogluconate (SSG), a Protein Tyrosine Phosphatase Inhibitor, Combined with Interferon Alpha for Patients with Solid Tumors. Journal of Cancer. 2011;2:81-9.

34. Borden EC, Sen GC, Uze G, Silverman RH, Ransohoff RM, Foster GR, et al. Interferons at age 50: past, current and future impact on biomedicine. Nature reviews Drug discovery. 2007;6:975-90.

35. Darnell J, Jr. Studies of IFN-induced transcriptional activation uncover the Jak-Stat pathway. J Interferon Cytokine Res. 1998;18:549-54.

36. Borden EC, Williams BR. Interferon-stimulated genes and their protein products: what and how? Journal of interferon \& cytokine research : the official journal of the International Society for Interferon and Cytokine Research. 2011;31:1-4.

37. Pani G, Fischer KD, Mlinaric-Rascan I, Siminovitch KA. Signaling capacity of the $\mathrm{T}$ cell antigen receptor is negatively regulated by the PTP1C tyrosine phosphatase. J Exp Med. 1996;184:839-52.

38. Burshtyn DN, Scharenberg AM, Wagtmann N, Rajagopalan $\mathrm{S}$, Berrada $\mathrm{K}, \mathrm{Yi} \mathrm{T}$, et al. Recruitment of tyrosine phosphatase HCP by the killer cell inhibitor receptor. Immunity. 1996;4:77-85.

39. Nakayama K, Takahashi K, Shultz LD, Miyakawa K, Tomita K. Abnormal development and differentiation of macrophages and dendritic cells in viable motheaten mutant mice deficient in haematopoietic cell phosphatase. Int J Exp Pathol. 1997;78:245-57.

40. Feinerman O, Veiga J, Dorfman JR, Germain RN, AltanBonnet G. Variability and robustness in $\mathrm{T}$ cell activation 
from regulated heterogeneity in protein levels. Science. 2008;321:1081-4.

41. Johnson KG, LeRoy FG, Borysiewicz LK, Matthews RJ. TCR signaling thresholds regulating $\mathrm{T}$ cell development and activation are dependent upon SHP-1. J Immunol. 1999;162:3802-13.

42. Carter JD, Neel BG, Lorenz U. The tyrosine phosphatase SHP-1 influences thymocyte selection by setting TCR signaling thresholds. Int Immunol. 1999;11:1999-2014.

43. Coggeshall KM, Nakamura K, Phee H. How do inhibitory phosphatases work? Mol Immunol. 2002;39:521-9.

44. Bryceson YT, March ME, Ljunggren HG, Long EO. Activation, coactivation, and costimulation of resting human natural killer cells. Immunol Rev. 2006;214:73-91.

45. Fan K, Zhou M, Pathak MK, Lindner DJ, Altuntas CZ, Tuohy VK, et al. Sodium stibogluconate interacts with IL-2 in anti-Renca tumor action via a $\mathrm{T}$ cell-dependent mechanism in connection with induction of tumorinfiltrating macrophages. J Immunol. 2005;175:7003-8.

46. Wang SF, Fouquet S, Chapon M, Salmon H, Regnier F, Labroquere $\mathrm{K}$, et al. Early $\mathrm{T}$ cell signalling is reversibly altered in PD-1+ T lymphocytes infiltrating human tumors. PloS one. 2011;6:e17621.

47. Monu N, Frey AB. Suppression of proximal T cell receptor signaling and lytic function in CD8+ tumor-infiltrating $\mathrm{T}$ cells. Cancer research. 2007;67:11447-54.

48. Peng C, Chen Y, Li D, Li S. Role of Pten in leukemia stem cells. Oncotarget. 2010;1:156-60.

49. Lazo JS, Wipf P. Small molecule regulation of phosphatase-dependent cell signaling pathways. Oncol Res. 2003;13:347-52.

50. Zhang ZY. Protein tyrosine phosphatases: structure and function, substrate specificity, and inhibitor development. Annu Rev Pharmacol Toxicol. 2002;42:209-34.

51. Zhuang Z, Lu J, Lonser R, Kovach JS. Enhancement of cancer chemotherapy by simultaneously altering cell cycle progression and DNA-damage defenses through global modification of the serine/threonine phospho-proteome. Cell Cycle. 2009;8:3303-6.

52. Kundu S, Fan K, Cao M, Lindner DJ, Tuthill R, Liu L, et al. Tyrosine phosphatase inhibitor-3 sensitizes melanoma and colon cancer to biotherapeutics and chemotherapeutics. Molecular cancer therapeutics. 2010;9:2287-96.

53. Kundu S, Fan K, Cao M, Lindner DJ, Zhao ZJ, Borden E, et al. Novel SHP-1 inhibitors tyrosine phosphatase inhibitor-1 and analogs with preclinical anti-tumor activities as tolerated oral agents. Journal of immunology. 2010;184:6529-36.

54. Mitsuhashi M. Ex vivo simulation of leukocyte function: stimulation of specific subset of leukocytes in whole blood followed by the measurement of function-associated
mRNAs. Journal of immunological methods. 2010;363:95100.

55. Berman JD, Grogl M. Leishmania mexicana: chemistry and biochemistry of sodium stibogluconate (Pentostam). Experimental parasitology. 1988;67:96-103. 